\title{
Simultaneous Determination of Thiamine and 2 -(1-Hydroxyethyl) thiamine in Biological Materials
}

\author{
Minoru Morita, Takashi Kanaya \\ and Tetuo Minesita ${ }^{1}$ \\ Shionogi Research Laboratory, Shionogi \\ and Co., Ltd. Osaka (Post No. 553)
}

(Received July 13, 1968)

\begin{abstract}
A precise and sensitive method for the fractional determination of thiamine and 2-(1-hydroxyethyl)thiamine (HET) in biological materials was described. Thiamine compounds in tissues were extracted by homogenizing and heating in an acidic medium, and dephosphorylated by phosphatase after deproteinization by metaphosphoric acid. The extract was partially purified by adsorption on permutit and elution with hot $\mathrm{KCl}-\mathrm{HCl}$ solution. HET in the eluate was determined by a thiochrome method using ferricyanide as the oxidizing agent after destroying thiamine by an alkaline incubation in the presence of a small amount of mercuric ion. Thiamine, on the other hand, was determined without interference of HET by a thiochrome method using mercuric chloride as the oxidizing agent. The reliability of this method was not appreciably affected by the molar ratio of thiamine and HET, and a small amount of HETicould be determined precisely in the presence of excess thiamine.
\end{abstract}

In a previous paper (1), it was reported that a considerable amount of 2-(1hydroxyethyl) thiamine (HET) pyrophosphate, a compound considered to be an intermediate in pyruvate metabolism by the thiamine diphosphate dependent enzymes, occurred naturally in mammalian tissues especially in muscular tissues such as heart, diaphragm and skeletal muscles. The finding was based upon the finding that the thiamine contents in these tissues as determined by the ferricyanide method (2) and cyanogen bromide method (3) showed different values. Thiamine gave an identical value by either method, whereas in these tissues higher thiamine values were always obtained by the ferricyanide method. On the other hand, HET was known to give thiochrome by oxidation with alkaline ferricyanide (4), but not with cyanogen bromide (5). Because thiamine gave thiochrome by either oxidizing agent, this difference in behavior might be used for the simultaneous determination of thiamine and HET in the mixture of the two (5). According to the methods.

\footnotetext{
1 森田 実, 金谷 尚, 峰下跠雄
} 
however, the amounts of HET were indirectly calculated by subtracting the value obtained by the cyanogen bromide method from that by the ferricyanide method. As a result, it is unavoidable to give an insufficient accuracy especially when HET is determined in the presence of excess thiamine. This study was undertaken to obtain a more reliable method for the respective determination of HET and thiamine without mutual interference.

\section{MATERIALS AND Methods}

\section{Reagents}

Thiamine - Thiamine standard solution containing $500 \mu \mathrm{g} / \mathrm{ml}$ of thiamine chloride hydrochloride in $0.01 \mathrm{~N}$ hydrochloric acid (manufactured by Takeda Pharmac. Ind., Osaka, and authorized by National Hygenic Lab., Japan) was used after appropriate dilutions.

HET — For a stock solution, crystalline DL-2-(1-hydroxyethyl)-thiamine ${ }^{2}$ was dissolved in $0.01 \mathrm{~N}$ hydrochloric acid $(500 \mu \mathrm{g} / \mathrm{ml})$, and appropriate dilutions were made of this solution.

$\mathrm{K}_{3} \mathrm{Fe}(\mathrm{CN})_{6}-1 \mathrm{w} / \mathrm{v} \%$ aqueous solution.

$\mathrm{BrCN}$ - Prepared just before use by adding $10 \% \mathrm{KCN}$ to saturated bromine water until the color disappeared.

$\mathrm{HgCl}_{2}-1 \mathrm{w} / \mathrm{v} \%$ aqueous solution was prepared. A $0.01 \%$ solution was obtained by 100 -fold dilution of this solution before use.

$\mathrm{NaOH}-30 \mathrm{w} / \mathrm{v} \%$ aqueous solution.

$\mathrm{KCl}-\mathrm{HCl}-25 \mathrm{w} / \mathrm{v} \% \mathrm{KCl}$ in $0.1 \mathrm{~N} \mathrm{HCl}$.

Sodium acetate $-4 M$ aqueous solution.

Acetate buffer - $0.1 M$ sodium acetate-acetic acid buffer, $\mathrm{pH} 4.5$.

Isobutanol — Reagent grade isobutanol was redistilled after shaking with 10 $\% \mathrm{NaOH}$ and dehydration with solid $\mathrm{NaOH}$. A $104-108^{\circ}$ fraction was collected.

Permutit - Vitachange (Permutit for thiamine determination, Wako Chem. Ind., Osaka), 60-80 mesh, was used after activation according to Hennessy (6).

Takadiastase — Takadiastase B for thiamine determination (Sankyo Co. Ltd., Tokyo) was dissolved in acetate buffer to make a $2 \%$ solution. Thiamine contaminated in Takadiastase was removed by shaking the solution with a small quantity of acid clay followed by centrifugation.

Metaphosphoric acid-10\% aqueous solution was prepared and stored in a refrigerator.

2. Preparation of Permutit Column

A specifically designed column, $12 \mathrm{~cm}$ long, $7 \mathrm{~mm}$ i.d. brown glass tube with a fused ground-glass stopcock on the bottom and a 30-ml reservoir on the top was used.

The activated permutit ( $1.5 \mathrm{~g}$ ) was packed in the column and approximately 30 $\mathrm{ml}$ of $5 \%$ acetic acid was passed through the column at a flow rate of $1 \mathrm{ml} / \mathrm{min}$. The column was then washed with about $60 \mathrm{ml}$ of boiling water (flow rate, $5 \mathrm{ml}$ / min), followed by passing $30 \mathrm{ml}$ of cold water. If the column was not used immediately, it was filled with water.

\section{Purification of Thiamine Compounds on Permutit}

The solution to be adsorbed was passed through the column at a flow rate of $1 \mathrm{ml} / \mathrm{min}$. After the column was washed with about $100 \mathrm{ml}$ of boiling water at a 
flow rate of $3 \mathrm{ml} / \mathrm{min}$, the thiamine compounds adsorbed on permutit were eluted with approximately $20 \mathrm{ml}$ of boiling $\mathrm{KCl}-\mathrm{HCl}$ at the same flow rate. The volume of the eluate was adjusted to exactly $25 \mathrm{ml}$ with $\mathrm{KCl}-\mathrm{HCl}$.

\section{Fluorometric Determination of Thiamine Compounds}

Modified ferricyanide method (for HET determination)_— A $5 \mathrm{ml}$ aliquot of $\mathrm{KCl}-\mathrm{HCl}$ solution containing 0.05 to $1 \mu \mathrm{g}$ of HET was taken into a glass-stoppered centrifuge tube and $2 \mathrm{ml}$ of $30 \% \mathrm{NaOH}$ and $0.1 \mathrm{ml}$ of $0.01 \% \mathrm{HgCl}_{2}$ were added successively. The mixture was kept standing at $25^{\circ}$ for $5 \mathrm{~min}$, then $0.2 \mathrm{ml}$ of $1 \%$ $\mathrm{K}_{3} \mathrm{Fe}(\mathrm{CN})_{6}$ was added. A $10 \mathrm{ml}$ aliquot of isobutanol was added and the mixture was shaken vigorously for $1 \mathrm{~min}$. Then, approximately $1 \mathrm{~g}$ of anhydrous $\mathrm{Na}_{2} \mathrm{SO}_{4}$ was added, and, after shaking for another $1 \mathrm{~min}$, the isobutanol layer was separated by centrifugation at $2000 \mathrm{rpm}$ for $5 \mathrm{~min}$. A blank test was done by omitting the addition of $\mathrm{K}_{3} \mathrm{Fe}(\mathrm{CN})_{6}$.

Cyanogen bromide method (for thiamine determination) — To a $5 \mathrm{ml}$ aliquot of $\mathrm{KCl}-\mathrm{HCl}$ solution containing 0.05 to $1 \mu \mathrm{g}$ of thiamine, $3 \mathrm{ml}$ of $\mathrm{BrCN}$ solution was added. After mixing, $2 \mathrm{ml}$ of $30 \% \mathrm{NaOH}$ was added and the thiochrome produced in the reaction mixture was extracted into isobutanol as described above. A blank test was done by adding the alkali prior to the addition of $\mathrm{BrCN}$.

Mercuric chloride method (for thiamine determination) - The procedure was the same as the cyanogen bromide method except that $0.2 \mathrm{ml}$ of $1 \% \mathrm{HgCl}_{2}$ solution was used in place of $3 \mathrm{ml}$ of $\mathrm{BrCN}$.

Fluorometry — A microspectrofluorometer (Hitachi, MPF-2A) was used throughout the experiments. Excitation and emission wavelengths were set at 375 and $420 \mathrm{~m} \mu$, respectively. The amounts of thiamine compounds in the sample were obtained by comparing the fluorescence intensity of the isobutanol extracted thiochrome with that obtained from a known amount of standard compound by the respective method.

\section{EXPERIMENTAL AND RESULTS}

\section{Determination of HET in Presence of Thiamine}

Stability of HET and thiamine in alkaline solution and effect of mercuric ion - To a $5 \mathrm{ml}$ aliquot of $\mathrm{KCl}-\mathrm{HCl}$ solution containing $1 \mu \mathrm{g}$ of thiamine or HET was added $2 \mathrm{ml}$ of $30 \% \mathrm{NaOH}$ with or without addition of $0.1 \mathrm{ml}$ of $0.01 \% \mathrm{HgCl}_{2}$ solution. The mixture was placed in a water bath maintained at $25^{\circ}$ for various times. After incubation, $0.2 \mathrm{ml}$ of $2 \% \mathrm{~K}_{3} \mathrm{Fe}(\mathrm{CN})_{6}$ was added, followed by extraction of thiochrome with $10 \mathrm{ml}$ of isobutanol and the fluorescence intensity was measured.

As shown in Fig. 1, thiamine was much more labile than HET on alkaline incubation. Addition of a small amount of mercuric ion remarkably accelerated the decomposition of thiamine, thus all the thiamine was destroyed within 5 min. HET, on the other hand, remained approximately $80 \%$ of the initial under the condition. The difference in stability of the thiamine compounds made it possible to determine HET selectively without interference of thiamine.

Effect of mercuric ion concentration on the destruction of thiamine - To obtain the optimum concentration of mercuric ion required for complete destruction 


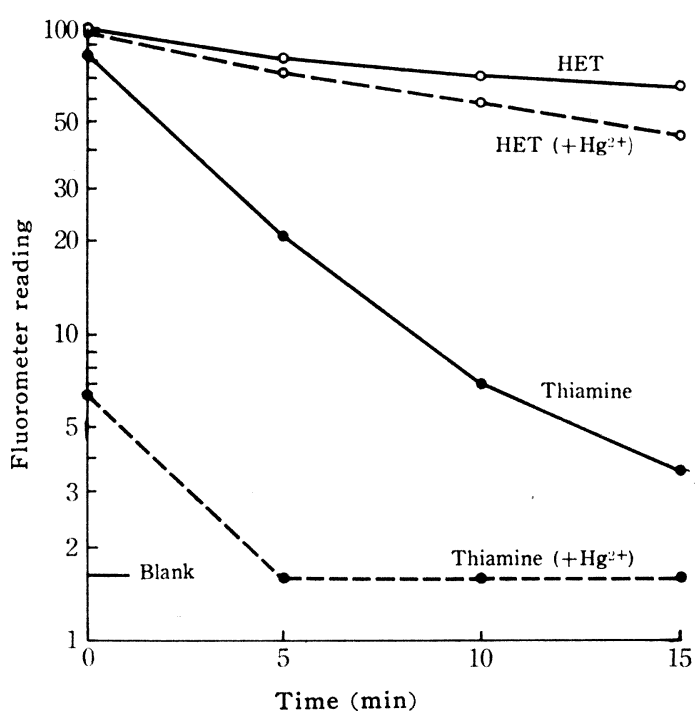

FIG. 1 Effect of Mercuric Ion on the Stability of Thiamine and HET in an Alkaline Solution

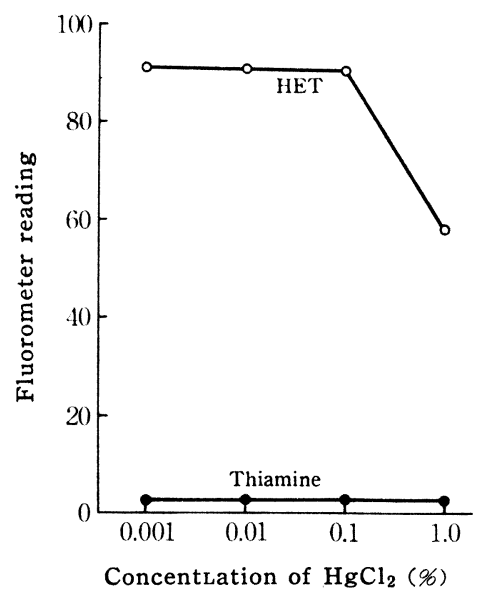

FIG. 2 Effect of Mercuric Chloride Concentration on the Thiochrome Formation from Thiamine and HET by the Modified Ferricyanide Method

of thiamine, a $0.1 \mathrm{ml}$ aliquot of $\mathrm{HgCl}_{2}$ solution in various concentrations was added to an alkaline solution of thiamine $(1 \mu \mathrm{g}$ in $5 \mathrm{ml}$ of $\mathrm{KCl}-\mathrm{HCl}$ plus $2 \mathrm{ml}$ of $30 \%$ $\mathrm{NaOH})$. After the mixture stood for $5 \mathrm{~min}$ at $25^{\circ}, 0.2 \mathrm{ml}$ of $2 \% \mathrm{~K}_{3} \mathrm{Fe}(\mathrm{CN})_{6}$ was added, and the fluorescence intensity of the isobutanol extracted thiochrome was measured (Fig. 2).

The minimal concentration of $\mathrm{HgCl}_{2}$ required for complete destruction of thiamine was less than $0.001 \%$. Thiochrome formation from HET was not affected by the addition of $\mathrm{HgCl}_{2}$ in concentrations ranging 0.001 to $0.1 \%$, though it was hindered by a higher concentration of $\mathrm{HgCl}_{2}$. In the following experiments, a $0.01 \%$ solution of $\mathrm{HgCl}_{2}$ was preferably used.

Effect of ferricyanide concentration on the thiochrome formation from HET - In the determination of HET under the above described conditions, the concentration of ferricyanide to be added was varied from 0.1 to $2.0 \%$ and the fluorescence intensities were compared. As shown in Fig. 3, a constant intensity was obtained independent of the ferricyanide concentration within the range of 0.1 to $2.0 \%$. However, because of the better reproducibility of the results, it is recommended to use a $1 \%$ solution of $\mathrm{K}_{3} \mathrm{Fe}(\mathrm{CN})_{6}$.

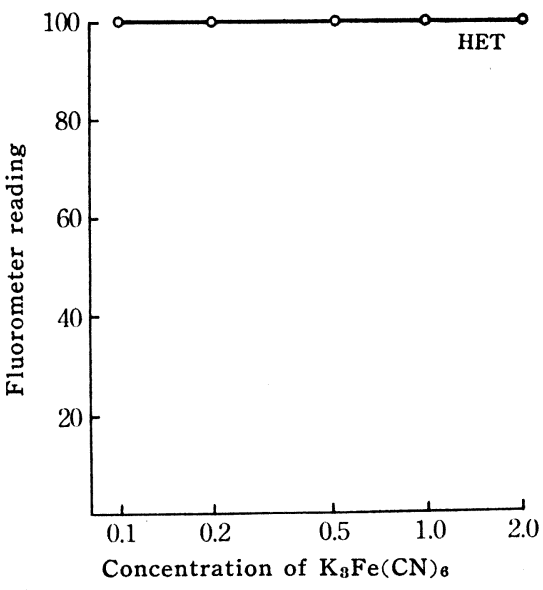

FIG. 3 Effect of Ferricyanide Concentration on the Thiochrome Formation from HET by the Modified Ferricyanide Method 


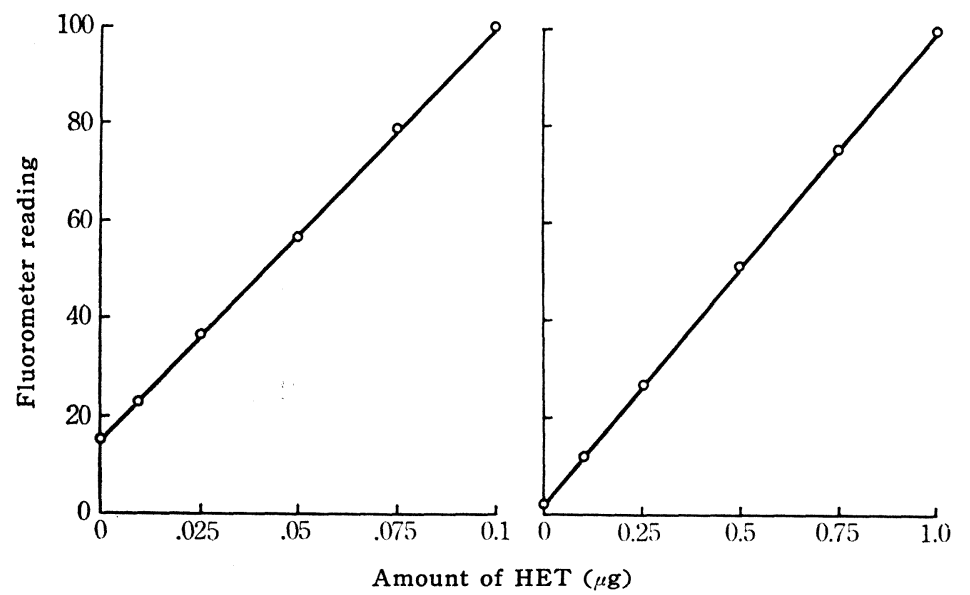

FIG. 4 Standard Curve of HET by the Modified Ferricyanide Method

Standard curve of HET by a modified ferricyanide method-From the above described results, a modified ferricyanide method was adopted for the determination of HET in the presence of thiamine. According to this method, the fluorescence intensity was strictly proportional to the amounts of HET in the range of 0.1 to $1 \mu \mathrm{g}$, or even in a low range of 0.01 to $0.1 \mu \mathrm{g}$ (Fig. 4). The lowest limit for detecting HET by this method was approximately $0.01 \mu \mathrm{g}$ per assay.

\section{Determination of Thiamine in Presence of HET}

Cyanogen bromide method — As suggested by Shiobara (5), thiamine might be determined by the cyanogen bromide method without interference of HET, if HET would not give any thiochrome by this method. However, $\mathrm{BrCN}$ was not completely unreactive toward HET. As shown in Table 1, approximately 4 or $5 \%$ of HET was converted into thiochrome by the cyanogen bromide method. Accordingly, if a large excess of HET was present with thiamine, the determined value of the latter would be considerably overestimated.

Mercuric chloride method — It had been reported by Katsumata (7) that $\mathrm{HgCl}_{2}$ could oxidize thiamine to thiochrome when it was used in place of $\mathrm{BrCN}$.

TABLE 1

Thiochrome formation from HET by mercuric chloride method or cyanogen bromide method

\begin{tabular}{ccc}
\hline \multirow{2}{*}{$\begin{array}{c}\text { HET } \\
\text { added }\end{array}$} & \multicolumn{2}{c}{ Thiochrome produced $a$} \\
\cline { 2 - 3 } & $\mathrm{HgCl}_{2}$ & $\mathrm{BrCN}$ \\
\hline$\mu g$ & \multicolumn{3}{c}{$\mu g$} \\
0.1 & 0.001 & 0.005 \\
0.5 & 0.009 & 0.024 \\
1.0 & 0.019 & 0.039 \\
5.0 & 0.177 & 0.377
\end{tabular}

$a$ Values are expressed as the equivalent amounts to thiamine- $\mathrm{HCl}$
TABLE 2

Thiochrome formation from thiamine and HET by mercuric chloride and alkali

\begin{tabular}{ccc}
\hline \hline \multirow{2}{*}{$\begin{array}{c}\text { Concn } \\
\mathrm{HgCl}_{2}\end{array}$} & \multicolumn{2}{c}{ of } \\
\cline { 2 - 3 } pluorometer & Thiamine & HET \\
\hline 0.01 & & \\
0.1 & 3.9 & 1.2 \\
0.5 & 25.5 & 1.3 \\
1.0 & 69.0 & 1.9 \\
2.0 & 94.5 & 2.7 \\
5.0 & 102 & 2.5 \\
Blank & 107 & 2.9 \\
& 1.2 & 1.2 \\
\hline
\end{tabular}


In order to apply this reagent for the quantitative determination of thiamine, concentrations of $\mathrm{HgCl}_{2}$ to be added in place of $\mathrm{BrCN}$ were examined (Table 2).

Almost equivalent fluorescence intensity to that of the cyanogen bromide method was obtained when $0.2 \mathrm{ml}$ of $1 \% \mathrm{HgCl}_{2}$ solution was added to a $5 \mathrm{ml}$ aliquot of $\mathrm{KCl}-\mathrm{HCl}$ solution containing $1 \mu \mathrm{g}$ of thiamine followed by the addition of $2 \mathrm{ml}$ of $30 \% \mathrm{NaOH}$. Although a slightly higher intensity was obtained if a higher concentration of $\mathrm{HgCl}_{2}$ was used, in which case a white precipitate of insoluble mercuric salt is formed, it is recommended to use a $1 \%$ solution.

Also, with this method, HET could hardly be oxidized to thiochrome, but it was still incompletely inert against $\mathrm{HgCl}_{2}$ and approximately $2 \%$ of $\mathrm{HET}$ was converted into thiochrome (Table 1). However, the degree of interference by HET by this method was considerably low as compared to the cyanogen bromide method. For this reason, the mercuric chloride method seemed to be preferable for the determination of thiamine in the presence of HET.

Standard curve of thiamine by mercuric chloride method - According to this method, straight lines were obtained when the relative fluorescence intensities, measured with 2 different levels of sensitivities $(0.1 \mu \mathrm{g}$ and $1 \mu \mathrm{g}$ in full scale), were plotted against the amounts of thiamine (Fig. 5).

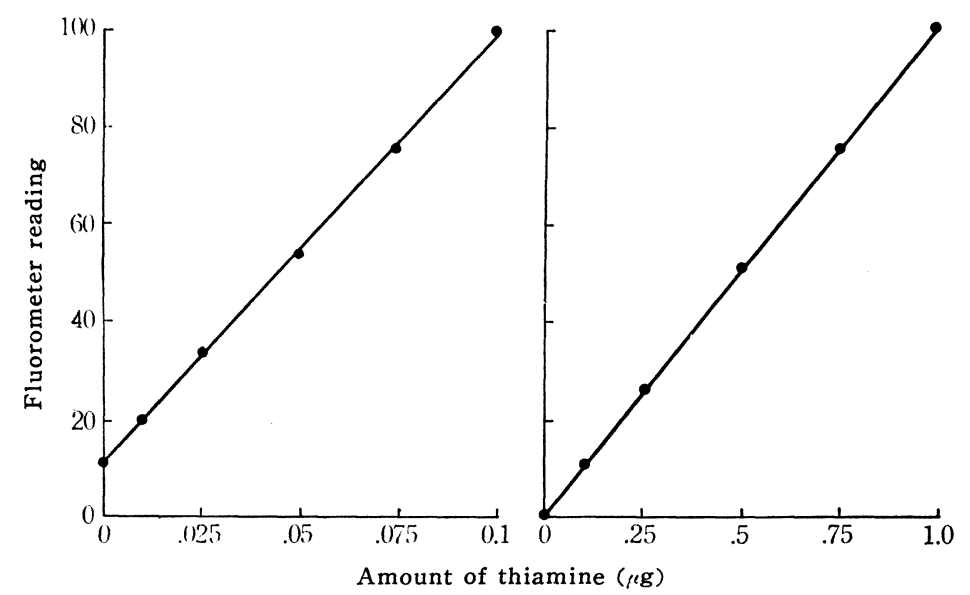

FIG. 5 Standard Curve of Thiamine by the Mercuric Chloride Method

\section{Separate Determination of Thiamine and HET}

Thiamine and HET were dissolved together in various concentration ratios in $\mathrm{KCl}-\mathrm{HCl}$ solution. A $5 \mathrm{ml}$ aliquot was taken and thiamine determined by the mercuric chloride method. HET was determined by the modified ferricyanide method for another $5 \mathrm{ml}$ aliquot. The results are shown in Table 3. Recovery of both thiamine and HET from the mixture was practically sufficient except for the $1: 10$ mixture in which thiamine was somewhat overestimated because of an interference of excess HET.

\section{Adsorption of HET on Permutit}

In order to apply the method for the determination of thiamine and HET in biological materials, it is necessary to separate the thiamine compounds from other 
TABLE 3

Separate Determination of Thiamine and $\mathrm{HET}$ Dissolved together in $\mathrm{KCl}-\mathrm{HCl}$ Solution

\begin{tabular}{cccccc}
\hline \hline \multicolumn{2}{c}{ Added } & & \multicolumn{2}{c}{ Found } \\
\cline { 1 - 1 } \cline { 5 - 6 } Thiamind & HET & & Thiamine & HET \\
\hline \multicolumn{3}{l}{$\mu g$} & & & \multicolumn{2}{c}{$\mu g$} \\
1.0 & 1.0 & & 0.976 & 0.958 \\
1.0 & 0.5 & & 0.971 & 0.479 \\
1.0 & 0.1 & & 0.943 & 0.102 \\
0.5 & 1.0 & & 0.498 & 0.987 \\
0.1 & 1.0 & & 0.110 & 0.989 \\
0.1 & 0.1 & & 0.100 & 0.105 \\
\hline
\end{tabular}

TABLE 4

Adsorption of HET on Permutit

\begin{tabular}{ccc}
\hline $\begin{array}{c}\text { HET } \\
\text { adsorbed }\end{array}$ & $\begin{array}{c}\text { HET } \\
\text { recovered }\end{array}$ & Recovery \\
\hline$\mu g$ & $\mu g$ & per cent \\
0.5 & 0.497 & 99.4 \\
1.0 & 0.994 & 99.4 \\
2.0 & 1.991 & 99.6 \\
5.0 & 4.888 & 97.8 \\
\hline
\end{tabular}

fluorescent substances. For this purpose, permutit has preferably been used in the determination of thiamine. HET could also be adsorbed on permutit and be eluted quantitatively by hot $\mathrm{KCl}-\mathrm{HCl}$ if the column of permutit was adequately prepared as described (Table 4).

5. Recommended Procedure for Biological Materials

Principle — Thiamine compounds in biological materials are extracted by homogenizing and heating in an acidic medium. After deproteinization with metaphosphoric acid, phosphorylated thiamine compounds are hydrolyzed with phosphatase and separated from other interfering materials by adsorption on permutit and elution with hot $\mathrm{KCl}-\mathrm{HCl}$. HET in the eluate is determined by a modified ferricyanide method, in which thiamine is completely destroyed by alkaline incubation in the presence of a small amount of mercuric ion prior to the determination of HET. Thiamine is determined by the mercuric chloride method for which HET remains unreactive.

Extraction - The extraction procedure for thiamine compounds is the same as reported previously (8).

A tissue sample, 0.5 to $2 \mathrm{~g}$ according to the content of thiamine compounds, is added to a test tube containing $10 \mathrm{ml}$ of $0.1 \mathrm{~N} \mathrm{H}_{2} \mathrm{SO}_{4}$, and placed in a boiling water bath for $5 \mathrm{~min}$ to inactivate the enzyme activities of the tissue. After cooling, it is homogenized and again heated in a boiling water bath for $15 \mathrm{~min}$ to make the extraction complete. To this extract, $5 \mathrm{ml}$ of $10 \%$ metaphosphoric acid is added followed by standing for $10 \mathrm{~min}$ to precipitate protein, and the $\mathrm{pH}$ of the extract is adjusted to 4.5 by the addition of $4 M$ sodium acetate solution. Water is added to make a final volume of $30 \mathrm{ml}$, and the mixture filtered or centrifuged. An aliquot of the filtrate $(20-25 \mathrm{ml})$ is taken and $4 \mathrm{ml}$ of $2 \%$ Takadiastase solution is added with few drops of toluene, followed by standing overnight at $37.5^{\circ}$ to hydrolyze the phosphorylated thiamine compounds.

Adsorption on permutit - The dephosphorylated extract is passed through a permutit column at a flow rate of $1 \mathrm{ml} / \mathrm{min}$. The column is washed with 100 to $120 \mathrm{ml}$ of boiling water (flow rate, $3 \mathrm{ml} / \mathrm{min}$ ), and the thiamine compounds are simultaneously eluted with approximately $20 \mathrm{ml}$ of boiling $\mathrm{KCl}-\mathrm{HCl}$ at the same flow rate. The volume of the eluate is adjusted to exactly $25 \mathrm{ml}$ by the addition of $\mathrm{KCl}-\mathrm{HCl}$.

Fluorometry — For the determination of HET, a $5 \mathrm{ml}$ aliquot of the eluate is taken, and $2 \mathrm{ml}$ of $30 \% \mathrm{NaOH}$ and $0.1 \mathrm{ml}$ of $0.01 \% \mathrm{HgCl}_{2}$ are added successively. After allowing the mixture to stand for exactly $5 \mathrm{~min}$ at $25^{\circ}, 0.2 \mathrm{ml}$ of $1 \% \mathrm{~K}_{3} \mathrm{Fe}(\mathrm{CN})_{6}$ 
is added, and the thiochrome produced in the reaction mixture is extracted into 10 $\mathrm{ml}$ of isobutanol. A blank test is done by omitting the addition of $\mathrm{K}_{3} \mathrm{Fe}(\mathrm{CN})_{6}$.

For the determination of thiamine, a $5 \mathrm{ml}$ aliquot of the eluate is mixed with $0.2 \mathrm{ml}$ of $1 \% \mathrm{HgCl}_{2}$ followed by addition of $2 \mathrm{ml}$ of $30 \% \mathrm{NaOH}$, and the thiochrome is extracted into $10 \mathrm{ml}$ of isobutanol. A blank test is done by adding $\mathrm{NaOH}$ prior to the addition of $\mathrm{HgCl}_{2}$.

With either method, a known amount of standard thiamine or HET dissolved in $5 \mathrm{ml}$ of $\mathrm{KCl}-\mathrm{HCl}$ is treated by the same procedure as the sample, and the isobutanol extracted thiochrome served as the standard. The amount of standard compound should be chosen so as to be close in concentration to that of the sample.

Galvanometer reading of the standard (a), excited at $375 \mathrm{~m} \mu$ light and emitted at $420 \mathrm{~m} \mu$, is set to a fixed scale and the readings of sample $(b)$ and blanks of sample $(c)$ as well as of standard $\left(c^{\prime}\right)$ are recorded. The content of thiamine compounds in the assay sample is calculated as follows:

$$
\frac{b-c}{a-c^{\prime}} \times \mu \mathrm{g} \text { standard used }=\mu \mathrm{g} / \text { assay }
$$

\section{Recovery from Biological Materials}

Known amounts of thiamine and HET were simultaneously added to $10 \mathrm{ml}$ of liver and heart homogenates of rat $\left(20 \%\right.$ in $\left.0.1 \mathrm{~N} \mathrm{H}_{2} \mathrm{SO}_{4}\right)$, and the recovery of either compound was tested in duplicate by carrying out the entire analytical procedure.

As shown in Table 5, recoveries of both thiamine and HET were practically agreeable with the added amounts.

TABLE 5

Recovery of Thiamine and HET Added to the Homogenate of Rat Tissues

\begin{tabular}{|c|c|c|c|c|c|c|}
\hline \multirow{2}{*}{ Tissue } & \multicolumn{2}{|c|}{ Added } & \multicolumn{2}{|c|}{ Found } & \multicolumn{2}{|c|}{ Recovery } \\
\hline & Thiamine & HET & Thiamine & HET & Thiamine & HET \\
\hline & \multicolumn{2}{|c|}{$\mu g$} & \multicolumn{2}{|c|}{$\mu g$} & \multicolumn{2}{|c|}{ per cent } \\
\hline \multirow{3}{*}{ Liver } & 0 & 0 & 2.595 & 0.302 & - & - \\
\hline & 0.5 & 1.0 & 3.119 & 1.297 & 104.8 & 99.5 \\
\hline & 1.0 & 0.5 & 3.658 & 0.801 & 106.3 & 99.8 \\
\hline \multirow{3}{*}{ Heart } & 0 & 0 & 1.243 & 0.481 & - & - \\
\hline & 0.5 & 1.0 & 1.729 & 1.489 & 97.2 & 100.8 \\
\hline & 1.0 & 0.5 & 2.213 & 0.960 & 97.0 & 95.8 \\
\hline
\end{tabular}

\section{Thiamine and HET Contents of Normal Rat Tissues}

Table 6 shows the results of the simultaneous determination of thiamine and HET in normal rat tissues. HET was found in almost every tissue except blood. As reported previously (1), high HET: thiamine ratios were found in muscular tissues such as heart, diaphragm and skeletal muscles. Smooth muscles such as intestine, on the contrary, contained less HET than the striated muscles. In those tissues such as liver, kidney and brain, HET concentrations were relatively low as compared to the thiamine concentrations, but it was certain that HET occurred not only in the muscular tissues but also in these tissues under normal and physiological condition. 
TABLE 6

Distribution of thiamine and HET in Tissues of Normal Rat

\begin{tabular}{|c|c|c|}
\hline \multirow{2}{*}{ Tissue } & \multicolumn{2}{|c|}{ Concentration in tissues $a$} \\
\hline & Thiamine & HET \\
\hline & \multicolumn{2}{|c|}{$\mu g / g$} \\
\hline Blood & $0.27 \pm 0.011$ & 0 \\
\hline Liver & $10.55+0.288$ & $1.35+0.118$ \\
\hline Kidney & $5.26 \pm 0.076$ & $0.93 \pm 0.050$ \\
\hline Cerebrum & $3.05 \pm 0.067$ & $0.54 \pm 0.027$ \\
\hline Heart & $5.42 \pm 0.212$ & $2.74+0.127$ \\
\hline Diaphragm & $3.33 \pm 0.142$ & $2.21 \pm 0.143$ \\
\hline M. gastrocn. & $1.17 \pm 0.083$ & $0.88 \pm 0.061$ \\
\hline Intestine & $2.55 \pm 0.127$ & $0.27 \pm 0.017$ \\
\hline
\end{tabular}

${ }^{a}$ Each value shows the mean of 5 determinations with its standard error.

\section{Discussion}

In the fluorometric determination of thiamine compounds, cyanogen bromide as well as mercuric chloride seemed to be more specific oxidizing agents for thiamine than ferricyanide. The latter oxidizes not only thiamine but also HET and pyrithiamine, both of which do not react against cyanogen bromide, and converted them into fluorescent substances. Making use of the differences in oxidizing ability of these reagents and in fluorescence spectra of the oxidation products, we have previously reported a sensitive method for the separate determination of thiamine and pyrithiamine in biological materials (8).

Application of this different oxidizing ability for the differential estimation of HET and thiamine was first investigated by Shiobara (5). Thiamine was directly determined by the cyanogen bromide method, and the total concentration of thiamine and HET was determined by the ferricyanide method. The amount of HET could be calculated by subtracting the thiamine value from the total value. However, if an excess amount of thiamine was present, and such a case would frequently be encountered in the determination of HET in biological materials, the difference in galvanometer readings between the cyanogen bromide method and the ferricyanide method would be so small that the reliability of estimating HET might not be satisfied.

To obtain more reliable method for determining HET in the presence of thiamine, the direct determination of HET without interference from thiamine would be necessary. In the preliminary experiments, it was found that HET was far more stable than thiamine in an alkaline solution, and that thiamine could successfully be destroyed without appreciable loss of HET by alkaline incubation in the presence of a small amount of mercuric ion. Based on these findings, a modified ferricyanide method by which HET could selectively be determined after complete destruction of thiamine followed by ferricyanide oxidation was developed. The reliability of this method was not affected by the molar ratio of thiamine and HET, and the sensitivity would be sufficient to apply the method for determining HET in biological materials. Interfering fluorescent substances in biological materials were successfully removed by adsorbing the thiamine compounds on permutit 
followed by elution with a $\mathrm{KCl}-\mathrm{HCl}$ solution. For the quantitative adsorption and elution of HET, the column should be prepared adequately as described, otherwise incomplete recoveries might be obtained. It seemed necessary to check the recovery for each brand or lot of permutit.

As previously reported (1), the existence of HET in muscular tissues which contained HET at a high rate was well demonstrated even by the indirect method. However, no reliable evidence for the natural occurrence of HET in other tissues was obtained by this method because the differences between the results obtained by the cyanogen bromide method and the ferricyanide method were so small that they were included within the variation of the results of determinations. In the present study, the distribution of HET in rat tissues was reinvestigated using the new method and it was demonstrated that HET occurred under physiological conditions not only in muscular tissues but also in almost every other tissue which was capable of metabolizing pyruvate. Only blood contained no HET. However, some uncertainties still exist as to whether all of the thiamine compounds which react against the modified ferricyanide method are HET, because many other hydroxyalkylthiamine analogs may possibly occur as intermediates of thiamine diphosphate dependent $\alpha$-keto acid metabolism. At the present time, there is no evidence to show the natural occurrence of hydroxyalkyl analogs of thiamine other than HET in animal tissues, and nothing is known concerning their physicochemical characteristics or chemical reactivities. In order to elucidate the specificity of the present method, further studies are necessary.

For the determination of thiamine in the presence of HET, mercuric chloride was found to be a better oxidizing agent than cyanogen bromide. HET could hardly be oxidized to thiochrome by either reagent but was not entirely unreactive. Approximately $5 \%$ of HET was converted to thiochrome by the cyanogen bromide method, thus it would be considerably overestimated if thiamine was determined in the presence of excess HET. Thiochrome formation from HET by the mercuric chloride method (approximately $2 \%$ ) was less than half as compared to that by the cyanogen bromide method. From the practical point of view, it would be rare to encounter a case where the amounts of HET in biological materials far exceeded that of thiamine, and the mercuric chloride method would give satisfactory results.

\section{REFERENCES}

1. Morita, M., Nishibe, Y., and Minesita, T., J. Vitaminol., 14, 230 (1968).

2. Nose, Y., Tashiro, T., and Kozuka, S., Seikagaku, 22, (1950).

3. Fuziwara, M. and Matsui, K., Anal. Chem., 25, 810 (1953).

4. Goedde, H. W., Blume, K. G., and Holzer, H., Biochim. Biophys. Acta, 62, 1 (1962).

5. Shiobara, Y., J. Biochem., 59, 76 (1966).

6. Hennessy, D. J., Ind. Eng. Chem., Anal. Ed., 13, 216 (1941).

7. Katsumata, M., Seikagaku, 28, 368 (1956).

8. Morita, M., Kanaya, T., and Minesita, T., J. Vitaminol., 14, 67 (1968). 